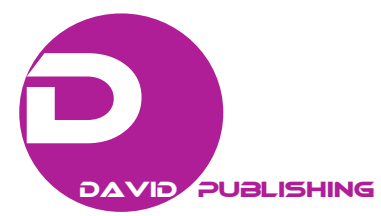

\title{
Prevalence of Hepatitis B Infection among Pregnant Women at Khartoum Teaching Hospital, Sudan
}

\author{
Mohammed Hammad Abuelgasim ${ }^{1}$ and Mohammed Basheer Koko Baraka ${ }^{2}$ \\ 1. Department of Emergency Medical Services, Al-Ghad International Colleges for Applied Medical Sciences, Tabuk 71491, KSA \\ 2. Al-Ghad International Colleges for Applied Medical Sciences, Tabuk 71491, KSA
}

\begin{abstract}
The aim of this study was to determine the prevalence of hepatitis B infection in pregnant women and to evaluate the risk factors of hepatitis B infection. The study was conducted during the period (March to June, 2010) in Khartoum state, Sudan. A total of 160 pregnant women who presented to the labor ward or antenatal clinic of Khartoum Teaching Hospital were enrolled. Socio-demographic characteristics were gathered, in addition to obstetric history through a structured questionnaire. Hepatitis B surface antigen was assayed using rapid test. The seropositivity among the studied population was 12 (7.5\%) for HBsAg (Hepatitis B surface antigen). Some of the studied risk factors were found to be statistically significant in relation to hepatitis B virus infection among Sudanese pregnant women in Khartoum state. The study concluded that HBV infection among pregnant Sudanese women is of high endemicity in Khartoum state.
\end{abstract}

Key words: Hepatitis B, pregnant women, prevalence.

\section{Introduction}

HBV (Hepatitis B virus) infection is a global public health problem. It is estimated that there are more than 350 million HBV carriers in the world, of whom roughly one million die annually from HBV-related liver disease [1]. Implementation of effective vaccination programs in many countries has resulted in a significant decrease in the incidence of acute hepatitis B. Nevertheless, hepatitis B remains an important cause of morbidity and mortality. The spectrum of clinical manifestations of HBV infection varies in both acute and chronic disease. During the acute phase, manifestations range from subclinical or anicteric hepatitis to icteric hepatitis and, in some cases, fulminate hepatitis. During the chronic phase, manifestations range from an asymptomatic carrier state to chronic hepatitis, cirrhosis, and hepatocellular carcinoma. Extrahepatic manifestations also can occur with both acute and chronic infection. The clinical

Corresponding author: Mohamed Hammad Abuelgasim Ahmed, M.D., research field: gastroentrolgy. E-mail: mhd.abuelgasim@gmail.com. outcome of HBV infection depends upon the age at infection, the level of $\mathrm{HBV}$ replication, and the immune status of the host. Viral hepatitis is the most common cause of jaundice in pregnancy, causative agents are hepatotropic viruses termed A, B, C, D and E. viral hepatitis during pregnancy is associated with high risk of maternal and fetal complications and it has been reported as a leading cause of maternal mortality in Sudan [2]. Prevalence of viral hepatitis during pregnancy varies considerably between different parts of the world, e.g., acute infection with HBV occurs at a rate of $1-2$ per 1000 pregnancies, and $0.5 \%-1.5 \%$ of pregnant women are chronic carriers of HBV [3]. Vertical transmission remains the key strategy in addition to vaccination to control the prevalence of the disease in specific regions.

\section{Methodology}

\subsection{Methods and Materials}

This was across-section study conducted at Khartoum Teaching Hospital, Sudan during the period of March to June, 2010. After an informed consent, all 
pregnant women attended the antenatal care visit were approached to participate in the study. A fixed questionnaire was applied to collect relevant socio-demographic characteristics of these women (age, education, gestational age, residence and occupation). Then venous blood was withdrawn in a syringe. Rapid test for HBV was used (Enzyme Immunoassay or EIA). SPSS was used for entry and analysis of data.

\subsection{Ethics}

The study was approved by the Ethics Committee of the Faculty of Medicine, Khartoum University and an informed consent was taken from the women.

\section{Results}

During the study period, one hundred and sixty pregnant Sudanese women were investigated for the presence of HBsAg and evaluating the risk factors for its acquisition. Prevalence of HBV infection was $7.5 \%$ (Fig. 1). The mean age of studied population was 28 years (Fig. 2). The mean of the parity was 3.34 (Table 1), most of the studied population was in the third trimester (Fig. 3). The majority of population was in higher secondary school level (Fig. 4). Most of the candidates were non workers (house wives). Only 2 (1.2\%) candidates were employee. Over $81.3 \%$ were residing in Khartoum (Fig. 5). 13 (8.1\%) candidates gave jaundice history while 147 (91.9\%) had no history (Fig. 6). only 3 (1.9\%) candidates gave history of blood transfusion (Fig. 7). None of the candidates had been screened for HBsAg before or had been vaccinated. 7.5\% of women were found to be positive of HBsAg (Fig. 1). The mean of the age, parity, and gestational age were not significantly different between those who are positive or negative for HBsAg. Relationship between potential risk factors and positivity for HBsAg (Table 1): The significant relationship between some risk factors and HBV infection was found, e.g., the study showed that 7 (58\%) from the total positive women had history of surgery, and there is significant relationship between mother history of surgery and positive HBsAg $(P=0.005) .5(41.7 \%)$ have history of jaundice, and there is significant relationship between mother history of jaundice and positive HBsAg $(P=0.000) .2(16.6 \%)$ women reported that there are histories of jaundice in their husbands, and there is significant relationship

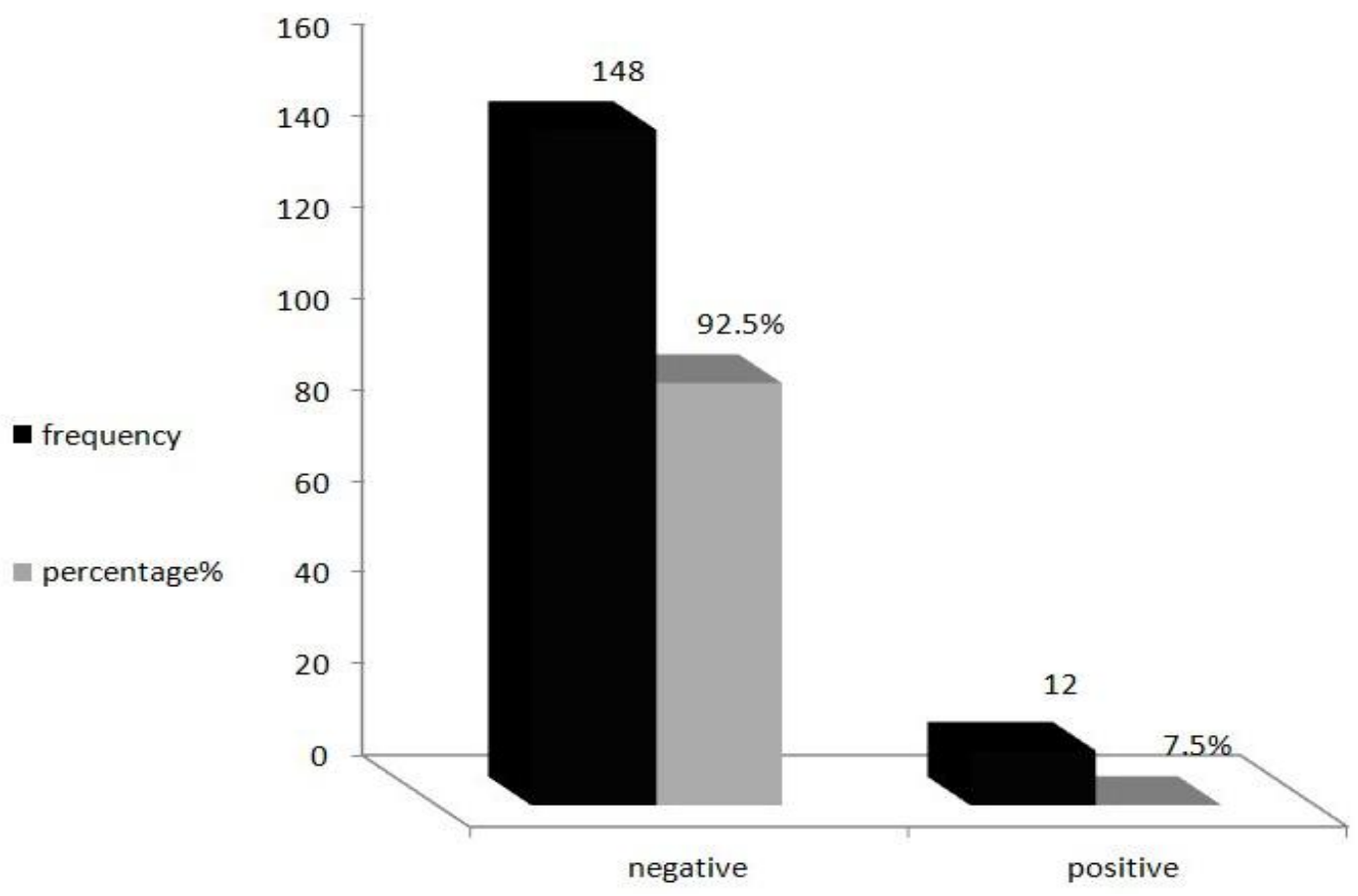

Fig. 1 Distribution of population according to HBsAg sero-status. 


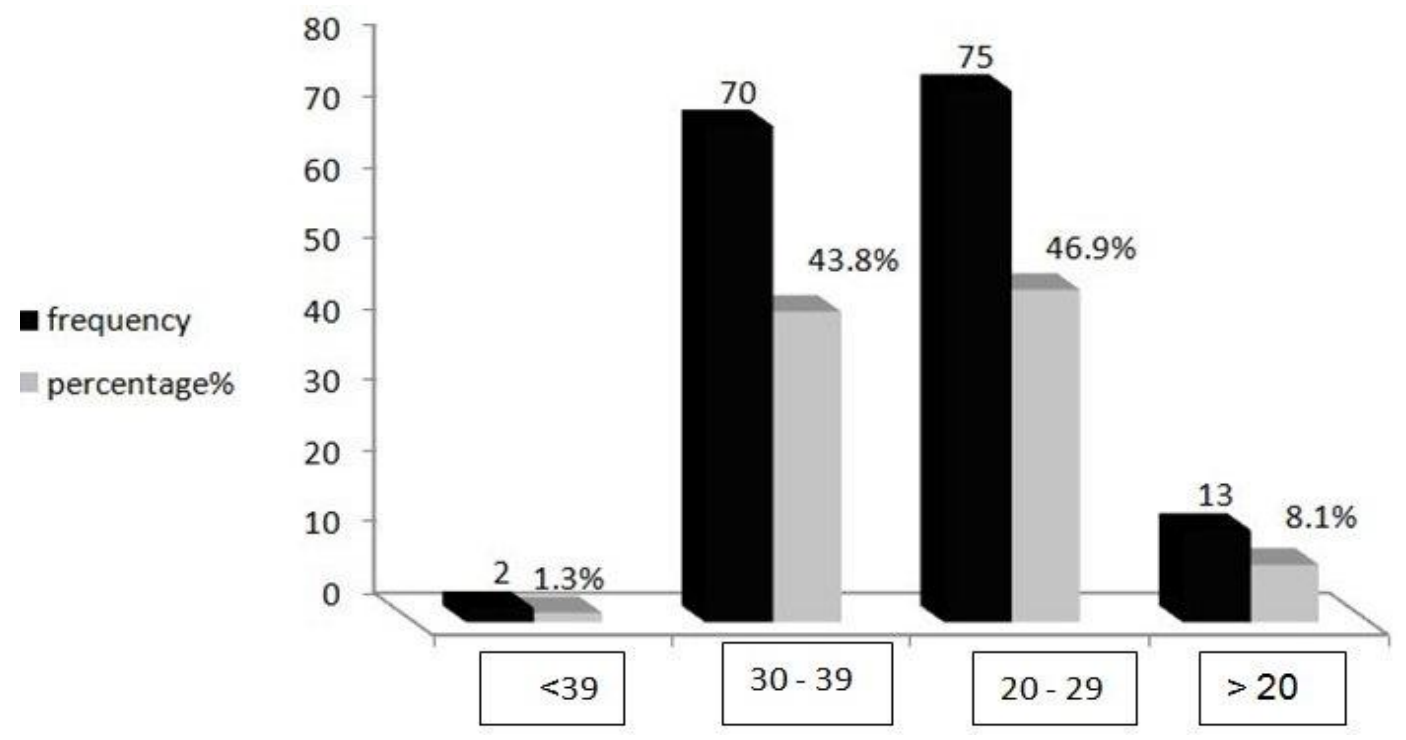

Fig. 2 Distribution according to age group.

Table 1 Statistical analysis of risk factors.

\begin{tabular}{lll}
\hline Risk factors & Mean & $P$ \\
\hline Parity & 3.34 & 0.144 \\
Age & 27.99 & 0.23 \\
History of jaundice in women & - & 0.00 \\
History of jaundice in husband & - & 0.00 \\
History of surgery & - & 0.005 \\
History of blood transfusion & - & 0.044 \\
Occupation & - & 0.044 \\
\hline
\end{tabular}

between history of jaundice in the husbands and positive HBsAg $(P=0.000)$. One $(3.3 \%)$ patient has history of blood transfusion, and there is significant relationship between mother blood transfusion and positive HBsAg $(P=0.044)$. Another one $(3.3 \%)$ works in medical field (nurse), and there is significant relationship between mother occupation and positive HBsAg $(P=0.044)$, no significant relationship between any group of age $(P=0.23)$, parity $(P=0.144)$ and positive HBsAg (Table 1).

\section{Discussion}

One hundred and sixty pregnant women were investigated for the presence of $\mathrm{HBsAg}$ and were evaluated for the risk factors for its acquisition. 12 (7.5\%) of the total population was positive for $\mathrm{HBsAg}$ representing high endemicity area. The epidemiological data of the general population in southern Sudan revealed prevalence of $26 \%$ for $\mathrm{HBsAg}$
[4], indicating in general that Sudan is endemic area for HBsAg. Worldwide sero-epidemiological studies for HBV infection in pregnant women varies considerably; some countries, e.g., Italy revealed a prevalence of only $1 \%$ [5], and that was considered relatively low when compared to a much highly endemic areas like Kenya and Egypt when the prevalence was estimated to be $9.3 \%$ and $15.3 \%$ respectively [6, 7]. Except for Oman which has the highest prevalence of $7.1 \%$ for HBs Ag sero-positivity, other gulf countries seem to have a low prevalence, as it is $2.4 \%$ in Saudi Arabia, 1\% in Qatar and $1.5 \%$ in UAE $[8,9]$. In Sierra Leone, Tanzania and Korea sero-positivity for $\mathrm{HBs} \mathrm{Ag}$ was found to be closely similar with a prevalence of $6.2 \%, 6.3 \%, 6.4 \%$, respectively [10-12]. In Egypt, it was found that maternal age and past history of blood transfusion were contributing factors for HBV infection [7]. Our study failed to establish any correlation between mother age and positivity for HBsAg, but a significant correlation was found between history of blood transfusion and positivity for $\mathrm{HBsAg}$. One (3.3\%) in 12 positive patients was found to have history of blood transfusion $(P=0.044)$. Study conducted in Nigeria found significant risk factors for hepatitis B infection among pregnant women and these factors include higher mean parity, higher number of sexual partners since sexual debut, poly gravity and previous positive history 


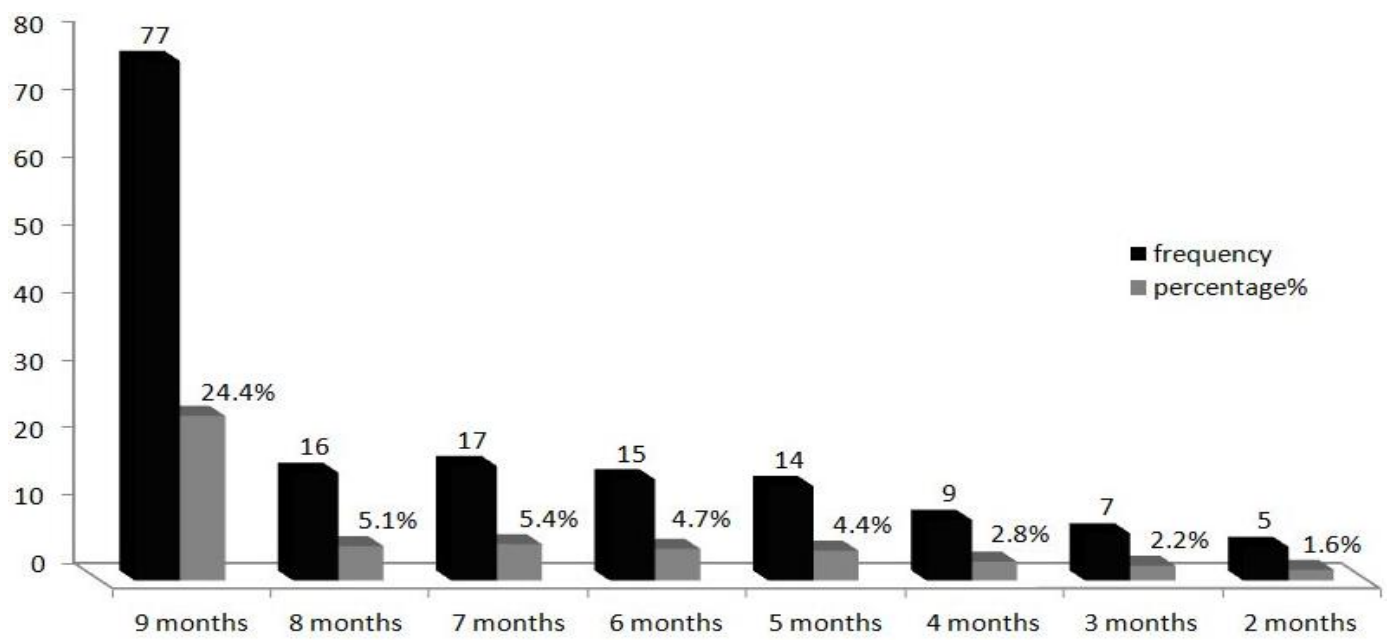

Fig. 3 Distribution of population according to gestational age

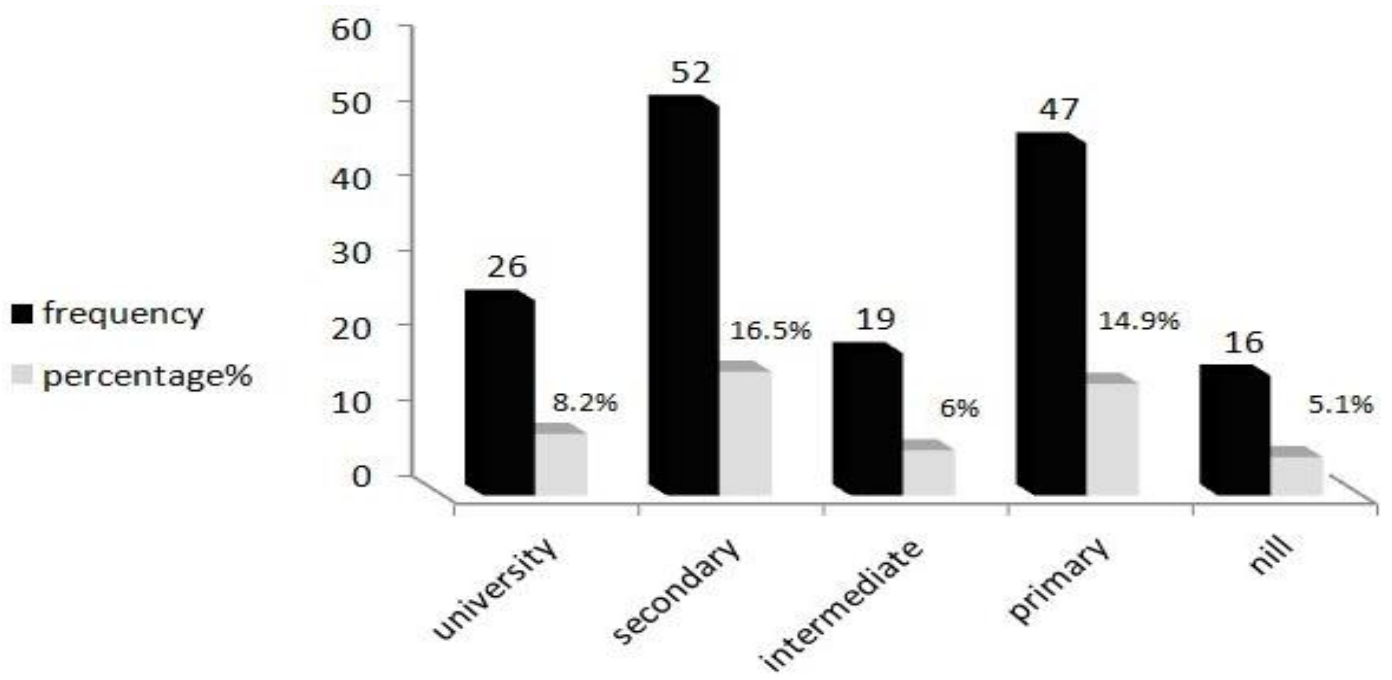

Fig. 4 Distribution of population according to educational level.

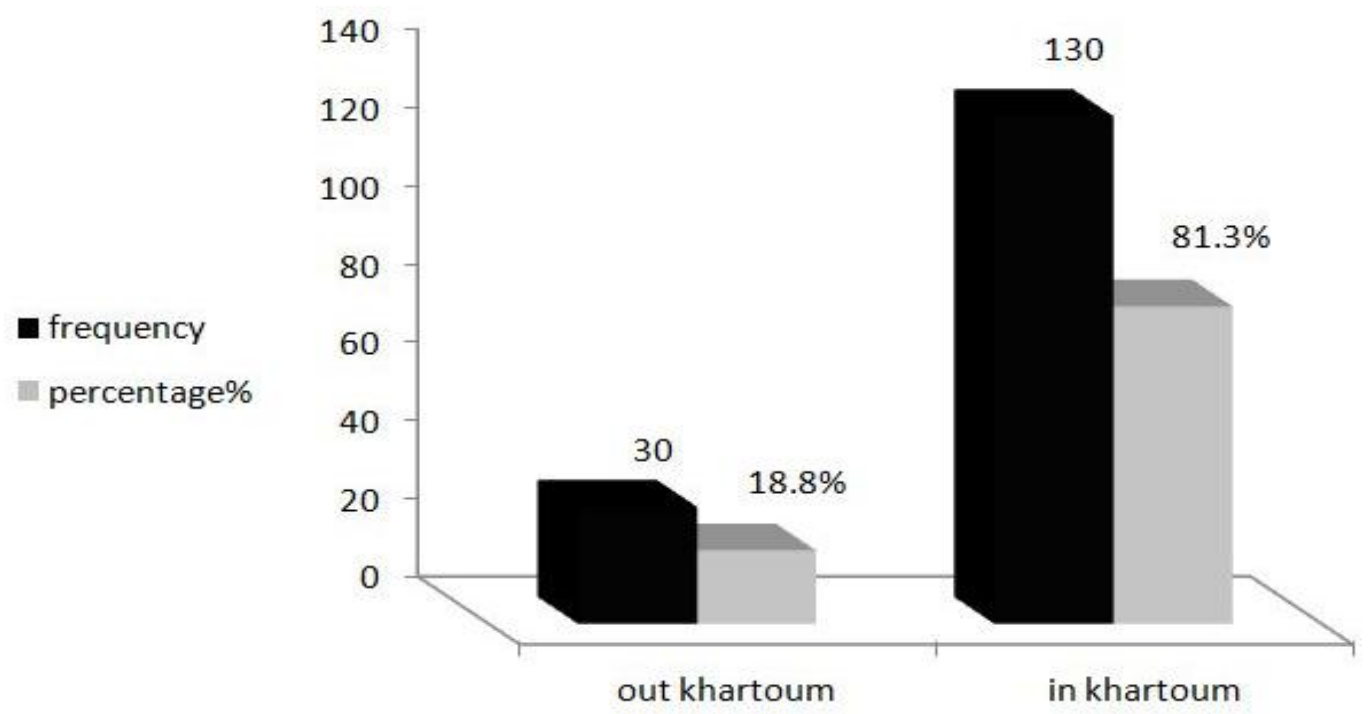

Fig. 5 Distribution of population according to residence. 


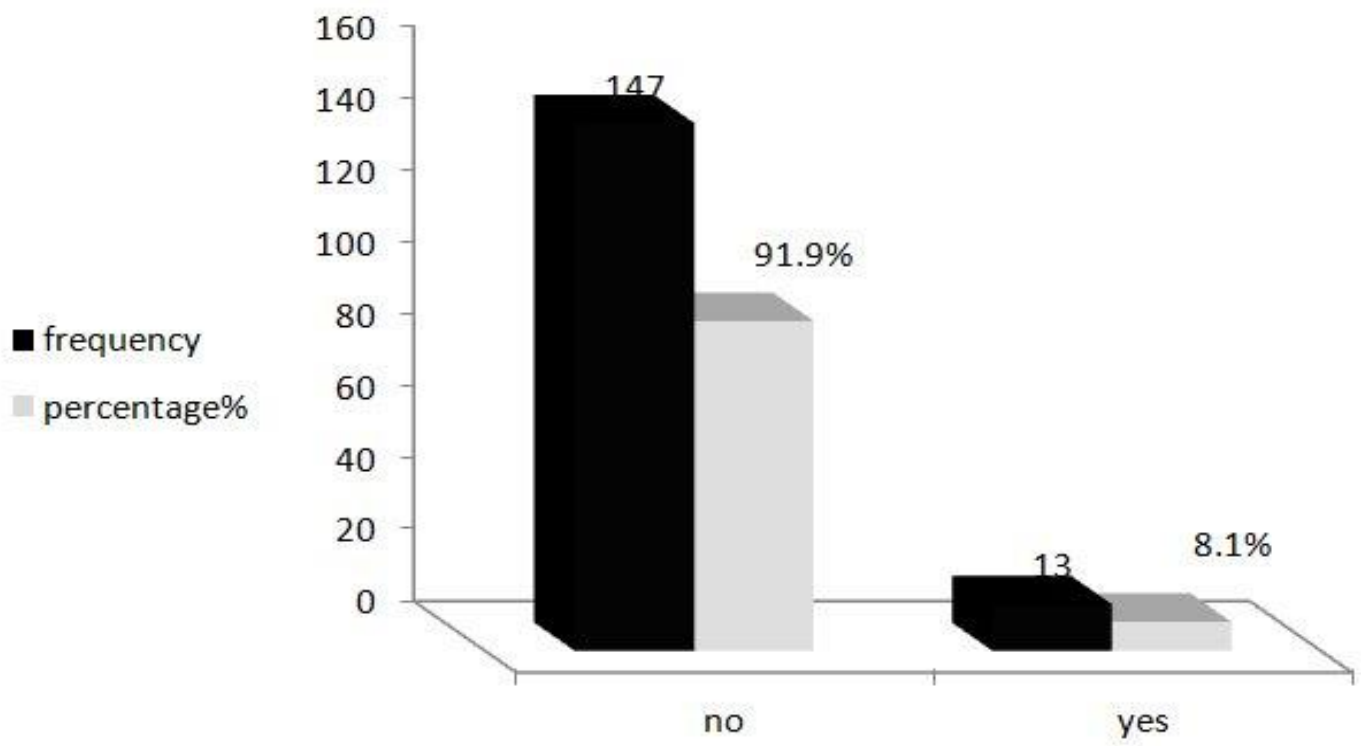

Fig. 6 Distribution of population according to history of jaundice

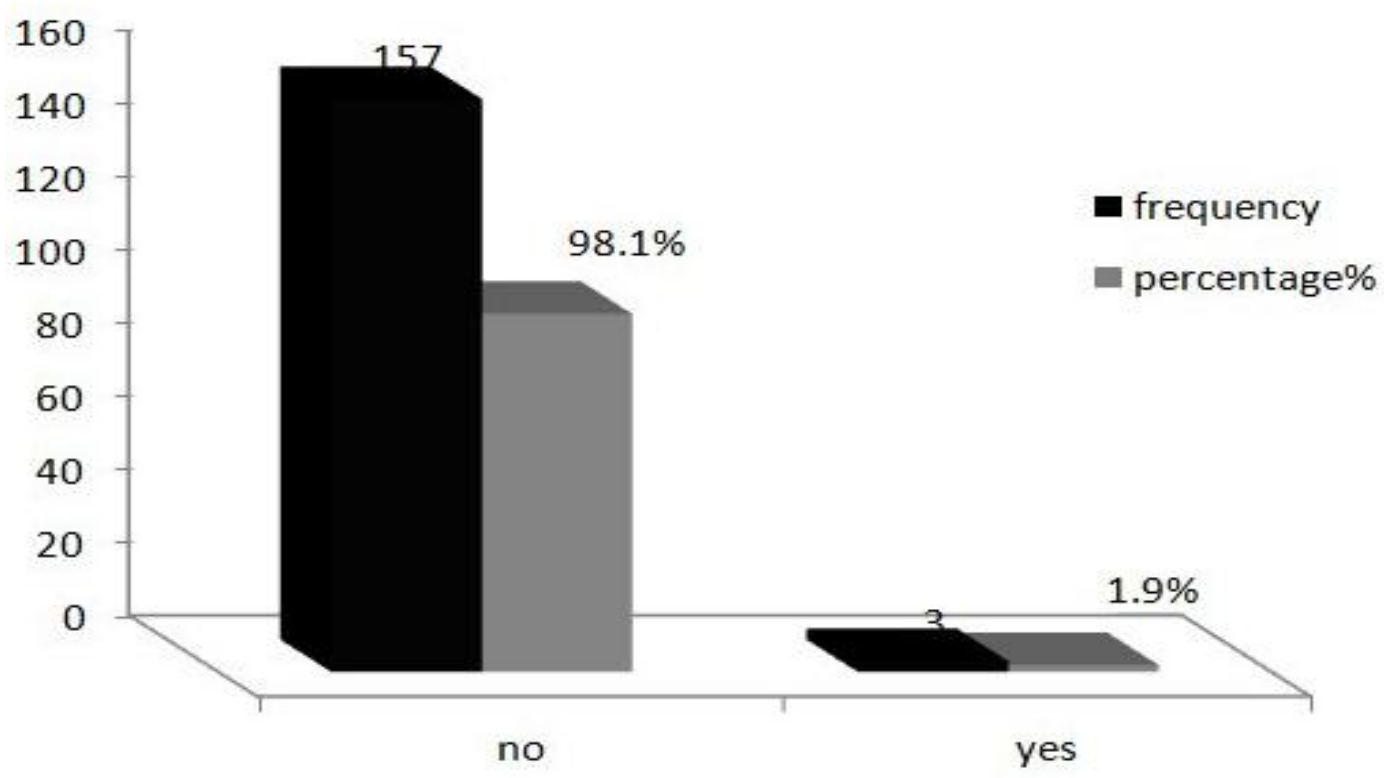

Fig. 7 Distribution of population according by history of blood transfusion

of sexual transmitted disease. Younger age was also found by some authors to be positively correlated with hepatitis B infection [9], but we didn't observe significant differences regarding age between both groups. Past history of jaundice is a risk factor for positive HBsAg. 5 (41.7\%) of positive patients have history of jaundice $(P=0.000)$. Studies showed that blood transfusion is a well established risk factor for HBsAg, and frequency of infection after one pint of blood was almost the same as after multiple transfusions [13]. There is significant relationship identified in this study between blood transfusion and risk of infection with $\mathrm{HB}(P=0.044)$. There is significant relationship found between past history of surgical operation and positive HBsAg $(P=0.005)$. Recently study conducted in Umm Dorman maternity hospital found that the prevalence of HBV infection among pregnant women was $5.7 \%$ and this was lower than the prevalence found in this study (7.5\%), also study found there were no identifiable risk factors 
found to be positively correlated with HBV infection among pregnant Sudanese women.

\section{Conclusion}

Data suggests a moderate to high prevalence of hepatitis B among Sudanese pregnant women. Hepatitis B virus infection represents a major problem affecting pregnant Sudanese women in Khartoum state.

There are many risk factors found to be positively correlated with HBV infection among pregnant Sudanese women in Khartoum state.

\section{References}

[1] Maynard, J. E. 1990. "Hepatitis B: Global Importance and Need for Control." Vaccine 8 (Suppl): S18.

[2] Dafallah, S. E., EL-Agib, F. H., and Bushra, G. O. 2003. "Maternal Mortality in Teaching Hospitals in Sudan." Saudi Medical Journal 24 (4): 369-72.

[3] Sookoian, S. 2006. "Liver Disease during Pregnancy: Acute Viral Hepatitis.” Ann. Hepato. 5 (3): 231-6.

[4] Mc Carthy, M. C., el-Tigani, A., Khalid, I. O., and Hyams, K. C. 1994. "Hepatitis B and C in Juba, Southern Sudan: Results of a Serosurvey." Trans. R. Soc. Trop. Med. Hyg. 88 (5): 534-6.

[5] Boldo, V., Floreani, A., Menegon, T., Grella, P., Paternoster, D. M., and Trivella, R. 2000. "Hepatitis C Virus, Hepatitis B Virus and Human Immunodeficiency Virus Infection in Pregnant Women in North-East Italy: A Sero-epidemiological Study." Eur. J. Epidemiol. 16 (1): 87-91.

[6] Okath, F., Mbuthia, J., Gatheru, Z., Murila, F., Kanyingi, F., Mugo, F., Esamai, F., Alavi, Z., Otieno, J., Kiambati,
H., and Wanjuki, N. 2006. "Sero-prevalence of Hepatitis B Markers in Pregnant Women in Kenya." East Afr. Med. J. 83 (9): 482-93.

[7] Badawy, H. A., and EL-Salahy, E. 2000. "Materno-Foetal Transmission of Hepatitis B Infection." J. Egypt Public Health Assoc. 75 (5-6): 357-67.

[8] AL-Mazron, Y. Y., AL-Jefrri, M., Khalid, M. K., AL-Ghamdi, Y. S., Mish Khas, A., BaKhsh, M., Eis, M., Nageeb, M., and Tumsah, S. 2004. "Screening of Pregnant Saudi Women for Hepatitis B Surface Antigen." Ann. Saudi. Med. 24 (4): 265-9.

[9] AL Awaidy, S., Abu-Elyazeed, R., AL Hosani, H., ALMulla, A., AL Busaiedy, S., AL Amiry, A., Farah, Z., AL Marrie, A., Back, H. L., AL-sheer, I., and Shah, S. 2006. "Sero-epidemiology of Hepatitis B Infection in Pregnant Women in Oman, Qatar and the United Arab Emirate." J. Infect. 52 (3): 203-6.

[10] Menendez, C., Sanchez-Tapias, J. M., Kahigwa, E., Mshinda, H., Costa, J., Vidal, J., Acosta, C. Lopez-Labrador, X., Olmeda, E., Novia, M., Tanner, M. Rodes, J., and Alonso, P. L. 1999. "Prevalence and Mother-to-Infant Transmission of Hepatitis Virus B, C, and E in Southern Tanzania." J. Med. Viral. 58 (3): 215-20.

[11] Kang, H. S., Song, B. C., Ji, C. X., Kim, S. Y., Kim, S. Y., and Kim, S. K. 2004. "Serologic Markers of Hepatitis B Virus in Pregnant Women in Jejo Island." Korean J. Hepatol. 10 (3): 191-6.

[12] Wurie, I. M., Wurie, A. T., and Gevao, S. M. 2005. "Sero-prevalence of Hepatitis B Virus among Middle to High Socio-economic Antenatal Population in Sieraleone." West Afr. J. Med. 24 (1): 18-20.

[13] Rizvi, T. J., and Fatima, H. 2003. "Frequency of Hepatitis B in Obstetric Cases." J. Coll. Physicians Surg. Pak. 13 (12): 688-90. 